Revista Iberoamericana, Vol. LXXVII, Núms. 236-237, Julio-Diciembre 2011, 1041-1049

\title{
LITERATURA Y PODER EN LA DÉCADA DEL TREINTA EN ARGENTINA. LA VISIÓN DEL ENSAYISTA EZEQUIEL MARTÍNEZ ESTRADA
}

\author{
POR \\ AdRIANA LAMOSO \\ Universidad Nacional del Sur
}

Cuando la voracidad elemental de la inteligencia es tan
honda que se la confunde con la voracidad trófica del
organismo, se compra o se escribe indistintamente un
libro o una compota. Al madurar con los años suelen
ocurrirnos otras correlativas confusiones: sentimos
necesidad de comer y leemos; comemos un manjar
apetitoso y sentimos una invencible repugnancia por
cualquier novelista fabricante de embutidos.
Ezequiel MartínezEstrada,La Cabezade Goliat(112-13)

Con esta frase sentenciosa cierra Martínez Estrada un pasaje de su ensayo La Cabeza de Goliat, en la que, con obvia claridad, alude a tensiones o conflictos inherentes al campo intelectual nacional, lo que reconduce a un repertorio de cuestiones vinculadas estrechamente con este dominio. Nos referimos a la compleja diagramación de los espacios culturales, en los que la construcción de la propia imagen va ligada a una amplia constelación de cuestiones, entre las que se incluyen las condiciones externas que regulan la práctica literaria.

¿Cuáles son los posicionamientos de los intelectuales argentinos que diseña Martínez Estrada a fines de la década del treinta? ¿Cómo representa las intervenciones de las instancias de poder? ¿Cuál es el lugar que le asigna a los lectores y al mercado? ¿Cómo se configura a sí mismo con relación a estas dinámicas? ¿Qué estrategias textuales selecciona para la definición de su postura? Estos interrogantes formarán parte nuclear del desarrollo del presente trabajo, menos para dar cuenta de la existencia de evidentes conflictos vinculados con el proceso de profesionalización del escritor y sus instancias de legitimación que para apreciar cómo el escritor construye, en la dimensión subjetiva, su lugar en tanto intelectual y el valor que le asigna al conjunto de fuerzas que condicionan la práctica literaria del momento. 


\section{FiguRACIONES ANTITÉTICAS}

En principio, el ensayista alude, con una economía léxica destacable, a la condición del escritor argentino en su interpretación de las raíces existenciales de la ciudad de Buenos Aires. La preocupación por la función que desempeñan se entrelaza estrechamente con las condiciones de posibilidad que el ejercicio del poder estatal les confiere. Subraya la presencia de puntuales factores que constituyen el blanco de ataque en el espacio polémico que el texto inaugura. La modalidad discursiva que Martínez Estrada adopta, como estrategia preponderante de confrontación, está constituida por la ironía, figura propia del pensamiento crítico, según lo destaca Max Bense, ${ }^{1}$ al referirse al lugar que adquieren los ensayistas, "naturalmente en el confinium entre el estadio de la creación y el estadio estético por un lado, y entre la tendencia y el estadio ético por el otro" (Bense 27). Puesto que puede considerarse a la ironía como ambigüedad y paradoja, realidad y apariencia, ataque y norma moral, constituye el modo retórico que el intelectual considera válido, para ejercer una denuncia que apunta por lo menos a un doble sistema de valores en pugna.

Por una parte, Martínez Estrada actualiza el panorama del país en lo que respecta a los vínculos entre los ámbitos culturales y comerciales, mediante la referencia directa al proyecto político e intelectual que desarrolló la generación del ochenta en Buenos Aires. Como contrapartida al desenvolvimiento de tales prácticas, construye una perspectiva ampliamente antitética y disidente respecto de la situación de la vida cultural en el presente nacional, que se circunscribe a la década del treinta. En este doble trayecto, que hace posible el procedimiento irónico, transitan disímiles representaciones que permiten traslucir conflictos en torno a posicionamientos ideológicos y éticos vinculados con la función del escritor y con la preocupación por el destino nacional.

Si tenemos en cuenta que entre 1935 y 1939 las tensiones y divisiones políticas se profundizaron en el país con el retorno del radicalismo a la escena electoral, el giro conservador del gobierno, la intensificación del fraude electoral y la mayor presencia de grupos antiliberales en el ámbito político (Nállim 122), con la puesta en práctica del modelo agro exportador, resultan identificables las impugnaciones que el ensayista profiere al gobierno nacional. El núcleo de la polémica se concentra en el programa

\footnotetext{
1 "Puesto que quien critica, quien debe necesariamente experimentar, debe generar las condiciones bajo las cuales pueda surgir con seguridad un nuevo tema, de manera distintiva respecto de cada autor, y por sobre todo probar la vigencia de su tema, ensayar, puesto que éste es ya con certeza el sentido de la reducida variación que un tema experimenta a través de sus críticos [...] la ley de la mínima modificación es también la misma ley bajo la cual trabaja el ensayista crítico; es también el método de su experimento. En este sentido contiene todo lo que cae bajo la categoría de pensamiento crítico: sátira, ironía, cinismo, escepticismo, razonamiento, nivelación, caricaturización, etc.” (Bense 27).
}

Revista Iberoamericana, Vol. LXXVII, Núms. 236-237, Julio-Diciembre 2011, 1041-1049
ISSN 2154-4794 (Electrónico) 
macroeconómico que prevalece y se expande sobre las políticas culturales que se imponen. Esta posición se pone de relieve en el siguiente enunciado de La Cabeza de Goliat:

El Gobierno dedica la misma atención a las artes y las letras que a la ganadería y la agricultura. Persigue con idéntica imparcialidad a los bichos dañinos y a los escritores perniciosos; a los buenos escritores les da oro a comer, designa a otros para que representen al país en cargos bien rentados, cuando hay langosta la combate y cuando muere un escritor extraordinario le edita las obras que dejó inéditas por falta de editor. De manera que andan las cosas bien barajadas. (112)

Mediante el doble juego del sentido que encubre la ironía, el ensayista expone su réplica a una política nacional que se apartaba con creces de los parámetros democráticos de respeto por las libertades individuales, en posible referencia a la prisión que sufrió un intelectual prestigioso como Ricardo Rojas, encarcelado, durante la presidencia de Justo, por su actividad dentro del partido radical, escritor con quien Martínez Estrada compartía su participación en la SADE. La compleja conformación del campo cultural nacional, en consonancia con las tensiones ideológicas de la época, se torna evidente en su análisis de las dinámicas de la vida cultural en su contemporaneidad. Las condiciones del campo intelectual se modifican hacia 1935, de tal modo que el movimiento historiográfico revisionista se consolida, y se difunde el nacionalismo político y cultural en sus distintas versiones e interviene la posición política y social de la Iglesia Católica Argentina (Nállim 122), con lo que el disenso entre los escritores se va tornando cada vez más amplio y profundo. ${ }^{2}$ La posible referencia al cierre de las trayectorias de Horacio Quiroga en 1937 y de Leopoldo Lugones en 1938, ${ }^{3}$ con sus suicidios, condensa la situación agobiante de una parte de la inteligencia nacional, con la que el ensayista se identifica.

2 En consonancia con esta afirmación, Beatriz Sarlo señala lo siguiente: "El mundo y la vida de los intelectuales cambia aceleradamente en los años veinte y treinta: al proceso de profesionalización iniciado en las dos primeras décadas de este siglo, sigue un curso de especificación de las prácticas y de diferenciación de fracciones. Los intelectuales ocupan un espacio que ya es propio y donde los conflictos sociales aparecen regulados, refractados, desplazados, figurados. El arte define un sistema de fundamentos: ‘lo nuevo’ como valor hegemónico, o ‘la revolución’ que se convierte en garantía de futuro y en reordenadota simbólica de las relaciones presentes” (Sarlo 28).

3 Ya han sido señaladas por la crítica las vinculaciones entre Lugones y Martínez Estrada, en especial se ha destacado la significativa importancia que revistió para el autor de Radiografía de la Pampa las intervenciones de Lugones en sus instancias de consagración como escritor, que se concretaron durante la década del veinte y se extendieron hasta 1932 con la entrega del Primer Premio Nacional de Letras respaldado por dicho intelectual, quien publicó ese mismo año en La Fronda un artículo titulado "En honor de Martínez Estrada", ya bajo el gobierno fraudulento del general Justo. A pesar de la disidencia ideológica entre ambos escritores, Martínez Estrada no modificará su relación con Lugones, aunque, en palabras de David Viñas, "recién después de 1930 la ambigüedad o la convivencia de esa década [1920] se irá disolviendo y polarizando” (Viñas 418).

ISSN 0034-9631 (Impreso) 
La presencia en el texto de un "nosotros" inclusivo frente "los demás", en el análisis de la situación del escritor argentino, permite abrir la interpretación hacia una problemática que encarna el reclamo de autonomía con respecto a las instancias del poder y el afianzamiento como actividad profesional al margen de otras esferas, ya que la imagen del escritor que construye Martínez Estrada encuentra una fuerte contrapartida en la figura del mercader, que, en el imaginario del ensayista, le gana la partida. Aunque no puede precisarse una división en dos bandos únicos, refiere la existencia básica de dos tipos de intelectuales, unos admiten la caracterización de 'artesanos' y otros de 'comerciantes'. En el espectro configurativo del primer grupo caben los escritores que abandonan el oficio porque "no quieren envilecer su trabajo" (Martínez Estrada, Cabeza 112), los que tienen que "transigir o que arrancarse la vida" (112) y los que se matan o se callan. En esta categoría incluye el "nosotros". En el segundo grupo, superior en cantidad al anterior, ubica a los que negocian "baratijas de mercachifle" (Martínez Estrada, Cabeza 112) y conforman el gremio de los comerciantes-sirena, ${ }^{4}$ entre los que piensa a los intelectuales que son funcionales con el poder político de turno, en tanto han aprendido lo que les "conviene traficar como principios morales, intelectuales y sociales” (110). Esta distinción trasluce las preocupaciones por el espacio social del escritor en su proceso de legitimación, y constituye un eco de las discusiones que se suscitaron entre los intelectuales, en distintas instancias de participación, como en el Primer Congreso de Escritores Argentinos, que la SADE organizó en Buenos Aires en noviembre de 1936, donde las tensiones se hicieron presentes, en torno a las controversias que tal cuestión ocasionaba (Nállim 122).

Martínez Estrada se inscribe en la categoría de "[...] escritor [que] es otra cosa: empleado, periodista, corredor de comercio, rentista, corrector de pruebas” (Cabeza 112). Esta afirmación junto con la idea de que "el carácter mercantil de una metrópoli no está en las cosas que compra y vende, sino en el signo lucrativo que imprime a sus acciones" (Martínez Estrada, Cabeza 113) señalan la importancia central que el escritor le asigna al valor mercantil de las producciones, de modo tal que su análisis de la situación del escritor argentino se encuentra fuertemente condicionado por tal parámetro evaluativo.

Las imágenes, que Martínez Estrada construye sobre sí mismo, presentan un arco de variabilidad que diseña la profundización de su beligerancia, conforme los escenarios políticos del país movilizan su sensibilidad.

\footnotetext{
4 Respecto del tipo 'sirena', Martínez Estrada aclara lo siguiente: “El tendero-sirena era ser humano desde la cabeza hasta el estómago y pescado desde el estómago hasta los pies. De busto correcto, su medio cuerpo no dejaba nada que desear desde el punto de vista de la elegancia; desde la parte exterior del mostrador el parroquiano no tenía nada que observar; pero la sirena no podía salir del mostrador sin peligro, porque como ése era su elemento, si lo abandonaba mostraba por fuerza la cola indecorosa: el tendero-sirena usaba levita de faldón largo para economizarse el uso de los pantalones, y zapatillas para ahorrarse las incomodidades del calzado; de modo que el mostrador servía para cumplir la parte menos bella pero no por eso menos interesante de la estatua” (Cabeza 110).

Revista Iberoamericana, Vol. LXXVII, Núms. 236-237, Julio-Diciembre 2011, 1041-1049 ISSN 0034-9631 (Impreso) 


\section{EL ESCRITOR APÓSTOL}

La construcción autofigurativa del ensayista no soslaya la presencia de una imagen que para el imaginario cultural de la época resulta inquietante: la figura del escritor profesional. Quien hace de la literatura su ocupación primordial parece, en apariencia, escapar de la categoría en la que se incluye Martínez Estrada y el grupo de los intelectuales a los que se refiere mediante una imprecisa generalidad. Ni amateur ni profesional, a la imagen del flâneur, que delinea en su prólogo a la segunda edición de La Cabeza de Goliat en 1946, antecede y, a la vez, se superpone la recurrente figura del guía moral, alejado de las corrupciones mundanas, aunque paradójicamente inserto en ellas, quien, con la posesión de facultades suprahumanas, hace uso de su clarividencia y revela las dinámicas ocultas al conjunto de los lectores. La representación del escritor profesional traduce un modo visible y concreto de relacionarse con la práctica literaria que, según su perspectiva, se entrelaza con los dispositivos del poder ${ }^{5}$ y se desenvuelve fundamentalmente en el marco de la táctica comercial. Ajeno, en su propia configuración, a estas dinámicas (a pesar del conocido éxito editorial que lo llevó a una pronta reedición de la obra y que, por otra parte, el mismo escritor hizo claramente público, sin excluir los sarcasmos, en el prólogo a la tercera edición de este ensayo) se construye en la imagen doliente del escritor solitario, que se encuentra privado de los 'beneficios' que gran número de intelectuales obtiene para sí, en virtud de un orden jerárquico validado por una constante tanto estrictamente comercial como política, de la que el ensayista se muestra excluido aunque, contradictoriamente, alude a una dinámica externa que lo expele, antes que a una voluntaria decisión de ubicarse al margen. Esta construcción de la distancia a partir de imperativos morales, que se muestra como penosa e injusta para el escritor, por una parte intenta validar sus dilucidaciones, a la vez que encubre una aspiración y un deseo, y por otra, se entrelaza con las figuraciones del escritor apóstol, que se tornan recurrentes a partir de la década del treinta en Argentina, en escritores de ascendencias ideológicas disímiles, como es el caso de Manuel Gálvez o de Jorge Luis Borges, tal como lo ha señalado ampliamente la crítica.

En el marco de estas representaciones, la búsqueda de una retribución material incluye el logro de una retribución simbólica. Aunque el éxito de ventas no conlleva en sí mismo, para Martínez Estrada, el rango de lo que considera valorativamente como 'literario’, el descrédito por la producción artística contemporánea, que adquiere plena difusión, encubre el deseo de tal alcance y también una consigna política que se cifra, en esta instancia, en destacar la cultura como un valor superior que debe apartarse

5 Sabido es el interés que estos vínculos suscitaron en los intelectuales argentinos del siglo xIx, en quienes Martínez Estrada, sin duda, asienta y profundiza su mirada. Nos referimos, en particular, a los representantes del Salón Literario del '37, como Echeverría, Alberdi, Gutiérrez y, fundamentalmente, Sarmiento.

Revista Iberoamericana, Vol. LXXVII, Núms. 236-237, Julio-Diciembre 2011, 1041-1049
ISSN 0034-9631 (Impreso) 
de su connivencia con la práctica política e institucional de turno, lo que la ubica indefectiblemente ‘del otro lado’. La crítica ha señalado la correspondencia del proyecto intelectual de Martínez Estrada con lo que podría denominarse "liberalismo aristocrático, espiritualista y cultural” (Terán 61), en tanto, por un lado, responde a la preocupación por la 'responsabilidad de los intelectuales' dentro del planteo general que presenta Julien Benda en La traición de los intelectuales, y, por otro, subraya la preeminencia de dos aspectos que en los ensayos de Martínez Estrada resultan tan evidentes como reiterados: el plano moral decadente en las situaciones que deben regenerarse, pero presente en el escritor que las denuncia, y el horizonte espiritual, casi metafísico, en el que se desenvuelven las intelecciones que únicamente el ensayista es capaz de revelar. ${ }^{6}$

Así como la retribución material aparece revestida de valores negativos, la simbólica conjuga un doble sentido semejante. En la condena a las prácticas de consumo del público lector se juegan las aspiraciones de los intelectuales de la época: por una parte, lograr la autonomía del campo literario respecto de las instituciones políticas, y por otro, conseguir el reconocimiento de la sociedad en lo que atañe tanto al lugar como a la producción y a la función significativa que en tal ámbito desempeñan. Las configuraciones de ambos tipos de intelectuales, mediante el recurso irónico, articulan la coexistencia de este doble sistema de valoración entre lo visible y lo deseable; a la par que constelan un núcleo complejo de problemas en el que intervienen variados actores y dinámicas sociales, entre los que el ensayista se instala desde una posición fuertemente polémica. Veamos cómo se refiere a la situación que enlaza producción y consumo:

Sólo una emulsión del apetito o de las necesidades elementales puede hacer confundir a un mercado con una librería. Sin embargo, hay quienes salen de casa con algunos pesos para comprar vituallas, se meten en una librería que les sale al paso, y vuelven con un paquete de lecturas; otros llevan el propósito de comprar libros y entran en cualquier mercado del camino y salen con un volumen de comestibles [...] Para conciliar ambos extremos hubo librería en Buenos Aires que vendió los libros por kilo y en algunos mercados envuelven las hortalizas con las mejores firmas de los suplementos literarios [...] Hay quienes tienen el cerebro caído en un prolapso que se percibe al tacto de sus producciones. Lo que puede explicar la confusión de los compradores y de los lectores. (Martínez Estrada, Cabeza 111)

\footnotetext{
6 Terán aclara que, a pesar de la amplia diversidad del grupo Sur en el que se encuentra Martínez Estrada, "[...] el grupo Sur destaca como valor supremo el de la cultura, y considera con Benda que el intelectual no debe involucrarse en las pasiones políticas inmediatas” (Terán 62). Un artículo que en 1933 publicó en sus páginas Leo Ferrero (“Carta de Norte América, ¿Crisis de elites?”) explicita la consigna: “El juego político no tiene nada que ver, en cierto sentido, con la actividad invisible y constante de las elites, que se realiza sobre un plano moral y -diría yo- casi metafísico” (Terán 62).

Revista Iberoamericana, Vol. LXXVII, Núms. 236-237, Julio-Diciembre 2011, 1041-1049
ISSN 2154-4794 (Electrónico)
} 
El ensayista se coloca al margen de la situación que percibe con claridad. Como tal, se concibe ajeno al éxito comercial, al consumo masivo, pero también se construye alejado de la precarización cultural que, bajo su visión, tal dinámica envuelve. En este sentido, el escritor se caracteriza por poner de relieve las prácticas de dominación del poder estatal y sus efectos sobre el público que consume las producciones literarias, de modo tal que las preferencias estéticas de los lectores contemporáneos responden a los condicionamientos políticos de la época, lo que relativiza la autonomía del campo y problematiza la función social del escritor.

La denuncia de Martínez Estrada prolonga las demandas y pretensiones de las clases medias argentinas por democratizar tanto el régimen político, como el acceso y la permanencia en las instituciones culturales, que la crítica reconoce como una aspiración de los intelectuales, desde la época del Centenario. Encarna también un reclamo que pone en el centro el interés por fortalecer y consolidar la profesionalización del escritor argentino en calidad igualitaria y al servicio del pueblo, en una década que se caracterizó por la reiterada sucesión de gobiernos dictatoriales.

\section{LECTORES Y MODERNIDAD}

Si consideramos las autoimágenes que el escritor construye de sí, podemos cotejar estas representaciones con las posiciones que el escritor ocupó en la época, para concluir que, en palabras de David Viñas, "de su marginalidad [...] nada o muy poco. Y más bien, todo lo contrario" (420), dado que entre 1930 y 1943 se registra una activa participación de Martínez Estrada en la vida literaria argentina. A lo anterior se le suma las importantes instancias de legitimación que significaron tanto la publicación de Radiografía de la Pampa en 1933, como los distintos premios literarios que recibió durante la década del veinte, en función de su producción poética: el Primer Premio de Literatura en 1921, en un certamen organizado por la Liga Patriótica Argentina, grupo de derecha liderado por Manuel Carlés; Tercer Premio Nacional de Literatura por Nefelibal en 1922; Primer Premio Municipal de Literatura por Argentina en 1927, que contó con el apoyo de Ricardo Rojas; Primer Premio Nacional de Literatura otorgado en 1929 por Títeres de pies ligeros, obra para teatro en verso que fue seleccionada gracias al auspicioso veredicto de Lugones, quien lo favoreció también en la obtención del Primer Premio Nacional de Literatura por Humoresca en el mismo año.

La alusión específica al campo de controversias agudiza la atención en la figura del lector, que, junto con la del comerciante, se encuentran envueltos en una gran comedia de equivocaciones. Tornar la mirada de ambos agentes hacia su perspicaz interpretación y postura política puede inferirse como una meta, que el autor configura a partir de la inclusión de la ironía, como herramienta constructiva eficaz. Es posible aludir, en este sentido, a las reflexiones que, a propósito del público lector de Radiografía, propone Liliana Weinberg, quien expresa:

\footnotetext{
Revista Iberoamericana, Vol. LXXVII, Núms. 236-237, Julio-Diciembre 2011, 1041-1049
ISSN 2154-4794 (Electrónico)
} 
[...] la elección de un género es también la elección de un tipo de lector. Martínez Estrada comienza a tomar conciencia de la existencia de un nuevo público: el lector de la calle, el consumidor de periódicos y revistas, ávido de tener acceso a nuevos temas que le sean presentados de manera no especializada [...] su obra como ensayista mucho tiene que ver con todo ello: ve en el ensayo una forma de "enseñar a leer”. (478-79)

La puesta en cuestión de la figura del lector (sin especificaciones de tipos ni de prácticas) puede pensarse en el marco de la ruptura del consenso, que fue llevada a cabo por intelectuales del treinta, respecto de las estrategias de modernización impulsadas por el poder político desde fines del siglo xIx, las que aparecen figuradas como una consecuencia negativa o como 'fallas' del programa que incluyó masivas campañas de alfabetización, y que fue emprendido, desarrollado y sostenido por los gobiernos con los que el ensayista es fuertemente polémico. ${ }^{7}$ La imagen oficial de la Argentina moderna es contrarrestada con visiones confrontativas que, por una parte, señalan la disidencia y, por otra, reconducen a la autoimagen del escritor solitario que se aparta de la alienación que las dinámicas del mercado imponen. A esta cuestión se suma, en el pensamiento del ensayista, el determinismo telúrico que se proyecta sobre la ciudad de la pampa y sus habitantes. Acción política y condicionamiento geográfico profundizan la inserción de la sociedad argentina en el caos irreparable. El señalado duelo entre inteligencia y política, inserto en el marco del debate sobre las raíces existenciales y espirituales de la gran urbe, no elude el golpe a las esferas que legislan en materia cultural y levanta la bandera de un selecto grupo de escritores que, sin particularizar, comparten con Martínez Estrada el escenario, construido como precario, de la oposición. Sin excluir las contradicciones y las paradojas, sus ensayos encarnan una voluntaria decisión de expandir el campo de recepción de su obra, de modo que resulte cada vez más visible y

\footnotetext{
Sarlo presenta un panorama claro y abarcativo respecto del crecimiento de Buenos Aires en las primeras décadas del siglo xx: "Buenos Aires era una ciudad cosmopolita desde el punto de vista de su población. Lo que escandalizaba o aterraba a muchos de los nacionalistas del Centenario influye la visión de los intelectuales en los años veinte y treinta. En verdad, el proceso había comenzado mucho antes, pero su magnitud y profundidad sigue impresionando a los porteños en este período. El ensayo traduce en términos ideológicos y morales las reacciones frente a una población diferenciada según lenguas y orígenes nacionales, unida a la experiencia de un crecimiento material rápido de la ciudad misma. Ya en 1890 se había quebrado la imagen de una ciudad homogénea, pero treinta años son pocos para asimilar, en la dimensión subjetiva, las radicales diferencias introducidas por el crecimiento urbano, la inmigración y los hijos de la inmigración. [...] Conflictos sociales extienden su fantasma sobre los debates culturales y estéticos. La cuestión de la lengua (quiénes hablan y escriben un castellano 'aceptable'); de las traducciones (quiénes están autorizados y por cuáles motivos a traducir); del cosmopolitismo (cuál es el internacionalismo legítimo y cuál una perversión de tendencias que falsamente se reivindican universales); del criollismo (cuáles formas responden a la nueva estética y cuáles a las desviaciones pintoresquistas o folklóricas); de la política (qué posición del arte frente a las grandes transformaciones, cuál es la función del intelectual, qué significa la responsabilidad pública de los escritores) son algunos de los tópicos presentes en el debate [...]”" (Sarlo 28).
}

Revista Iberoamericana, Vol. LXXVII, Núms. 236-237, Julio-Diciembre 2011, 1041-1049

Revista Iberoamericana, Vol. LXXVII, Núms. 236-237, Julio-Diciembre 2011, 1041-1049
ISSN 2154-4794 (Electrónico)


compartida su cosmovisión. En esta línea puede pensarse el diseño peculiar del habitante de Buenos Aires en su relación con el capital cultural nacional y, en particular, con los escritores del país.

Para finalizar, ha sido posible apreciar cómo, en un ensayo que se dedica primariamente a indagar en los rasgos enigmáticos de la ciudad capital, se actualizan las arduas disputas que envolvieron a los intelectuales argentinos en una continua y tan variable como compleja línea que atravesó distintas épocas. El proceso de profesionalización del escritor y la ubicación del ensayista en perfiles ideológicos, culturales y políticos no siempre exactamente coincidentes se ponen de relieve, a partir de configuraciones discursivas en las que cobra especial importancia la construcción de la propia imagen y la de los restantes escritores del país, así como su vinculación con esferas extraliterarias. Es posible, entonces, apreciar en el ensayo del cuarenta las preocupaciones, tensiones y problemáticas que se esconden tras marcos interpretativos dedicados, en principio, a dilucidar cuestiones no específicas del campo cultural nacional.

\section{BiBLIOGRAFÍA}

Benda, Julien. La traición de los intelectuales. Santiago de Chile: Ercilla, 1941.

Bense, Max. Sobre el ensayo y su prosa. Martha Piña, trad. México: CCYDEL-UNAM, 2004.

Martínez Estrada, Ezequiel. La Cabeza de Goliat. Microscopía de Buenos Aires. Barcelona: Losada, 2001.

Radiografía de la Pampa. Leo Pollmann, coord.México: Consejo Nacional para la Cultura y las Artes, Colección Archivos, 1993.

Nállim, Jorge. "De los intereses gremiales a la lucha política: la Sociedad Argentina de Escritores (SADE), 1928-1946”. Prismas. Revista de Historia Intelectual 7/7 (2003): 117-38.

Sarlo, Beatriz. Una modernidad periférica: Buenos Aires 1920 y 1930. Buenos Aires: Nueva Visión, 2003.

Terán, Oscar. "Ideas e intelectuales en la Argentina, 1880-1980". Ideas en el siglo. Intelectuales y cultura en el siglo XX latinoamericano. Terán, coord. Buenos Aires: Siglo XXI, 2004. 13-95.

Viñas, David. "Martínez Estrada, de Radiografía de la Pampa hacia el Caribe". Radiografía de la Pampa. Leo Pollmann, coord. México: Consejo Nacional para la Cultura y las Artes, Colección Archivos, 1993. 409-23.

Weinberg, Liliana. "Radiografía de la Pampa en clave paradójica”. Radiografía de la Pampa. México: Consejo Nacional para la Cultura y las Artes, Colección Archivos, 1993. 471-90.

Revista Iberoamericana, Vol. LXXVII, Núms. 236-237, Julio-Diciembre 2011, 1041-1049 
